\title{
Kefir İlavesinin Yonca Silajlarının Fermantasyon Özellikleri ve Aerobik Stabilitesi Üzerine Etkileri
}

Fisun $\mathrm{KOÇ}^{1}{ }^{\mathscr{8}}$, Bahattin KARAPINAR ${ }^{2}$, Berrin OKUYUCU ${ }^{3}$, Duygu KORUCU ERDEM ${ }^{4}$

1,2,3Tekirdağ Namık Kemal Üniversitesi Ziraat Fakültesi Zootekni Bölümü, Tekirdağ, ${ }^{4}$ Tekirdağ Namık Kemal Üniversitesi Ziraat Fakültesi Gıda Mühendisliği Bölümü, Tekirdağ

${ }^{1}$ https://orcid.org/0000-0002-5978-9232, ${ }^{2}$ https://orcid.org/0000-0002-6051-7023, ${ }^{3}$ https://orcid.org/0000-0001-8322-5050

${ }^{4} \mathrm{https}$ ://orcid.org/0000-0003-0728-5937,

$\square:$ fkoc@nku.edu.tr

\section{ÖZET}

$\mathrm{Bu}$ araştırmada, farklı dozlarda kefir ilavesinin yonca silajlarında fermantasyon gelişimi ve aerobik stabiliteleri üzerindeki etkileri araştırılmıştır. Katkı maddelerinin ilavesinden sonra, yaklaşık $500 \mathrm{~g}$ örnek plastik torbalara konularak sıkıştırılmış ve vakumla içindeki hava alınmıştır. Her grup için 10'ar tane olmak üzere toplam 70 paket silaj laboratuvar şartlarında $\left(25-30{ }^{\circ} \mathrm{C}\right) 45$ gün fermantasyona bırakılmıştır. Silolama döneminin sonunda (45. gün) tüm silajlara 7 gün süre ile aerobik stabilite testi uygulanmıştır. Araştırmada ayrıca fermantasyonun 45. günü ve aerobik stabilite dönemi sonrası baskın olan laktik asit bakteri türleri tespit edilmiştir. Sonuç olarak, yonca silajına ilave edilen kefir silajların $\mathrm{pH}$, asetik asit, bütrik asit, propiyonik asit içeriklerini, kuru madde kaybını düşürürken, laktik asit içeriklerini kontrol grubuna göre arttırmıştır $(\mathrm{P}<0.001)$. Silajların lactobacilli ve maya içerikleri kontrol grubuna göre artarken, küf gelişimini ise tamamen engellemişdir $(\mathrm{P}<0.001)$. Diğer

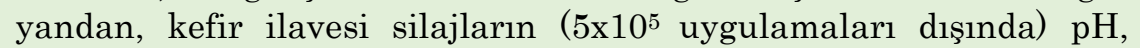
maya içeriklerini, $\mathrm{CO}_{2}$ üretimlerini düşürerek aerobik stabilitelerini ise geliştirmiştir $(\mathrm{P}<0.001)$.

\section{Araştırma Makalesi}

$\begin{array}{ll}\text { Makale Tarihçesi } \\ \text { Geliş Tarihi } & : 13.09 .2019 \\ \text { Kabul Tarihi } & : 08.11 .2019\end{array}$

\section{Anahtar Kelimeler}

Kefir

Laktik Asit Bakterisi

Silaj

Tanımlama

\section{The Effects of Kefir Addition on the Fermentation Characteristics and Aerobic Stability of Alfalfa Silages}

\begin{abstract}
In this study, the effects of different doses of kefir on the fermentation characteristics and aerobic stability of alfalfa silages were investigated. After the addition of the additives, approximately $500 \mathrm{~g}$ of sample was placed in plastic bags and compressed. A total of 70 packages, 10 for each group, were allowed to ferment for 45 days in laboratory conditions $\left(25-30{ }^{\circ} \mathrm{C}\right)$. The aerobic stability test was applied to the silages opened on the $45^{\text {th }}$ day for 7 days. Chemical and microbiological analyzes were performed on the samples opened on the $45^{\text {th }}$ day of fermentation. In addition, after silage fermentation of 45 days and aerobic stability period, lactic acid bacteria were identified. As a result, added kefir decreased $\mathrm{pH}$, acetic acid, butyric acid, propionic acid content, dry matter loss, whereas increased lactic acid content significantly compared to control group $(\mathrm{P}<0.001)$. Lactobacilli and yeast contents of silages increased compared to control group, also completely prevented the growth of mold $(\mathrm{P}<0.001)$. On the other hand, kefir (except $5 \times 10^{5}$ applications) decreased $\mathrm{pH}$, yeast contents, $\mathrm{CO}_{2}$ production and improved aerobic stability of alfalfa silages $(\mathrm{P}<0.001)$.
\end{abstract}

\section{Research Article}

$\begin{array}{ll}\text { Article History } & \\ \text { Received } & : 13.09 .2019 \\ \text { Accepted } & : 08.11 .2019\end{array}$

\section{Keywords}

Kefir

Lactic acid bacteria

Silage

Identification

To Cite : Koç F, Karapınar B, Okuyucu B, Korucu Erdem D, 2020. Kefir İlavesinin Yonca Silajlarının Fermantasyon Özellikleri ve Aerobik Stabilitesi Üzerine Etkileri. KSU Tarım ve Doğa Derg 23 (2): 535-542. DOI: 10.18016/ksutarimdoga.vi.620292. 


\section{GİRIŞ}

Silaj fermantasyonu kısmen kontrolsüz bir işlemdir pekçok faktör fermantasyon ve aerobik stabilite dönemi üzerinde etkili olmaktadır. Silajlık materyalin kimyasal ve mikrobiyolojik kompozisyonu değişkendir ve bu da silaj kalitesi üzerinde etkilidir (McDonald ve ark. 1991). Son yillarda, silaj fermantasyonu garanti altına almak, silaj kalitesini artırmak ve silajın daha iyi korunmasını sağlamak amacıyla silaj katkı maddesi olarak, laktik asit bakteri (LAB) inokulantlarının kullanımı yaygınlaşmıştır. Ancak LAB inokulantların etkinliği konusunda, silaj kalitesini artırdığı (Arriola ve ark., 2015; Silva ve ark., 2016; Cebe Hotun ve ark., 2019) ya da yeterli düzeyde etki göstermedikleri yönünde farklı görüşler bulunmaktadır (Kleinschmit ve ark., 2005). Bu olumsuzlukların, ticari inokulantlardaki LAB'ların kompozisyonundan kaynaklanabileceği yönünde görüşlerde bulunmaktadır (Kung ve Muck, 1997; Muck ve Kung, 1997). Bu anlamda bakıldığında silaj fermantasyonunda etkili olan LAB türleri ve etkinlikleri önem kazanmaktadır. Kefir bileşiminde LAB ve mayaların bulunduğu, üretiminde kefir tanesi veya starter kültürlerin kullanıldığı fermente bir süt ürünü olarak tanımlanmaktadır (Özpınar, 2012). Kefir tanesinde LAB (lactobacilli, lactococci ve leuconostoc), asetik asit bakterileri (acetobacter) ve mayaları karışım halinde bulundurur. Bu mikrobiyel karışım içinde en çok laktobasiller yer alır (\%65-80). Kefirin içerdiği lactobasil ve diğer bakteri türleri arasinda $L$. acidophilus, $L$. brevis, $L$. casei, $L$. fermentum, L. helveticus, L. kefiri, L. parakefiri, L.S lactis ve L.c mesenteroides bulunur. Son yapılan araştırmalar, kefirin bakteriyel florasını oluşturan LAB'lerinin silaj fermantasyonu üzerinde özellikle besin madde kayıplarını azalttığı ve aerobik stabilite üzerinde olumlu etkilerinin olduğu yönündedir (EFSA, 2013; Zwielehner ve ark., 2014; Daniel ve ark., 2015). Bu çalışmanın amacı, farklı dozlarda doğal ve ticari kefir kültürü ilavesinin yonca silaj fermantasyonu ve aerobik stabilite üzerine etkilerini ortaya koymaktır.

\section{MATERYAL ve METOT}

\section{Materyal}

Bu araştırmada silaj materyali olarak Namık Kemal Üniversitesi Ziraat Fakültesi Araştırma ve Uygulama Merkezinde yetiştirilen yonca (Medicago sativa) bitkisi kullanılmıştır. Silajı yapılacak yonca hasılları yaklaşık \%10 çiçeklenme başlangıcında hasat edilmiştir. Hasad edilerek 12 saat süreyle soldurulan yonca, silaj makinesiyle yaklaşık $1.5-2.0 \mathrm{~cm}$ boyutlarında parçalanmıştır. Katkı maddesi olarak,

1. Doğal kefir kültürü (DK): Doğal kefir kültürünün biyolojik kompozisyonuna ilişkin tanımlama yapılmıştır. Tanımlama sonrasında
Enterococcus faecalis, Lactobacillus brevis ve Micrococcus luteus içerdiği tespit edilmiştir.

2. Ticari kefir kültürü (TK): Biyolojik kompozisyonunda Lactococcus lactis subsp, Lactis biovar diacetylactis, Lactobacillus brevis, Leuconostoc spp.mesenteroides ve Saccharomoyces cerevisiae içeren (MYStarter KF) kullanılmıştır. Doğal ve ticari kefir uygulamalarında doz $10^{5}, 5 \times 10^{5}$ ve $1 \times 10^{6}$ seviyesinde olacak şekilde hesaplanmıştır.

\section{Katkı maddesinin uygulama şekli}

$10 \mathrm{~kg}$ parçalanmış taze materyal $1 \mathrm{x} 4 \mathrm{~m}$ temiz bir alana yayılmıştır. 1. grup kontrol grubu olup katkı maddesi içermemektedir. 2. grupta, doğal ve ticari kefir kültüründen $0.0375 \mathrm{~g}$ tartılarak üzerine $20 \mathrm{ml}$ çeşme suyu konarak iyice karışması sağlandıktan sonra taze materyal üzerine homojen bir şekilde el pülverizatörü ile püskürtülmüştür. 3. grupta 0.1875 g, 4. grupta 0.375 g 2. grupta açıklandığı gibi taze materyale uygulanmıştır. Kontrol grubuna diğer muamele gruplarına eşdeğer $20 \mathrm{ml}$ çeşme suyu ilave edilmiştir. Katkı madelerinin ilavesinden sonra, yaklaşık $500 \mathrm{~g}$ örnek plastik torbalara konularak sıkıştırılmış ve vakumla içindeki hava alınmıştır. Her grup için 10'ar tane olmak üzere toplam 70 paket silaj laboratuvar şartlarında $\quad\left(25-30 \quad{ }^{\circ} \mathrm{C}\right) \quad 45$ gün fermantasyona bırakılmıştır. Kırk beşinci gün açılan silajlara 7 gün süre ile aerobik stabilite testi uygulanmıştır.

\section{Kimyasal Analizler}

Fermantasyonun 45. gününde açılan silajlarda $\mathrm{pH}$, kuru madde (KM), laktik asit (LA), asetik asit (AA), bütirik asit (BA), propiyonik asit (PA) suda çözünebilir karbonhidratlar (SÇK), amonyağa bağlı nitrojen $\left(\mathrm{NH}_{3}-\mathrm{N}\right)$, mikrobiyolojik kompozisyona ilişkin olarak laktik asit bakterileri (LAB), maya ve küf sayımları yapılmıştır. Araştırmada $\mathrm{pH}$ ve tampon kapasitesi (Tk) analizleri Playne ve Mc Donald (1966), KM analizi Akyıldız (1984), $\mathrm{NH}_{3}-\mathrm{N}$ ve SÇK analizleri Anonim (1986), ve LA analizi Koç ve Coşkuntuna (2003)'nın bildirdiği şekilde yapılmıştır. AA, BA ve PA analizi ise Supelco (1998) tarafindan bildirilen yönteme göre gaz kromatografisi (GC-15A, Shimadzu, Japonya) ile yapılmıştır. Silajların KM kayıpları, 45. günlerde torbalarında hesaplanan silaj KM'si ağırlığının, torbalara konulan taze materyalin KM ağırlığına oranlanması ile hesap edilmiştir.

\section{Mikrobiyolojik Analizler}

Laktik asit bakterileri, maya ve küf yoğunluğunun belirlenmesinde Seale ve ark. (1990)'nın önerdiği yöntem takip edilmiştir. 


\section{Silaj Örneklerinden İzole Edilen Laktik Asit} Bakterilerinin Tanımlaması

16SrRNA Dizi Analizi tekniği kullanılmıştır. LAB tanımlamalarına ilişkin analizler Tekirdağ Namık Kemal Üniversitesi (NABİLTEM) merkezi araştırma laboratuvarında yapılmıştır.

\section{Aerobik Stabilite}

Kırkbeş günlük silolama süresi sonunda silaj örneklerine 7. gün sonunda Ashbell ve ark. (1991) tarafından önerilen yönteme göre aerobik stabilite testi uygulanmıştır. Ayrıca aerobik stabilite döneminde silaj örneklerindeki sıcaklık değişimleri ve ortam sıcaklığ 7 gün süreyle 2 saatte bir hobo pentant data logger ile takip edilmiştir (Chen ve ark., 1994).

\section{İstatistiksel Analizler}

Araştırma sonunda elde edilen veriler SPSS v.16 istatistik paket programının (SPSS Inc. 2007) GLM prosedüründe değerlendirilmiştir. Grup ortalamaları arasındaki farklılıkların karşılaştırılmasında Duncan testi kullanılmıştır (Efe ve ark., 2000).

\section{BULGULAR}

\section{Silajların Fermantasyon Özelllikleri}

Taze yoncaya ait kimyasal ve mikrobiyolojik analiz sonuçları Çizelge 1 ve Çizelge 2 ' de verilmiştir. Yonca bitkisinin $\mathrm{pH}$, Tk değeri, KM içindeki HP ve SÇK, LAB ve maya içerikleri sirasıyla $7.50, \quad 445$ $\mathrm{mEq} / \mathrm{kg} / \mathrm{KM}, \% 21.14,15.45 \mathrm{~g} / \mathrm{kg} \mathrm{KM}, 5.30,8.08 \mathrm{cfu} / \mathrm{g}$ arasında bulunmuştur.

Fermantasyonun 45. gününde açılan yonca silajlarına ait kimyasal analiz sonuçları Çizelge 1 'de verilmiştir. Erken çiçeklenme döneminde hasat edilen yonca silajlarının KM içeriği \%23.3 g/kg iken 12 saatlik soldurma sonrasında \%30.46 olmuştur. Fermantasyon 45. gününde KM içerikleri 27.25-31.54 arasında değişmiştir. Çalışmada, fermantasyonun 45 . gününde muamele grubundaki tüm silajlarının KM düzeyinin kontrol grubu silajlara göre daha yüksek olduğu belirlenmiştir $(\mathrm{P}<0.001)$.

Çalışmada, yoncaya kefir ilave edilmesi silajların pH'larını kontrol grubuna göre önemli düzeyde düşürmüştür $\quad(\mathrm{P}<0.001)$. Silajların başlangıç materyalinde 7.50 olan $\mathrm{pH}$ değeri kefir ilavesi ile muamele gruplarında $5.45-5.90$ arasında değişim göstermiştir.

Kefir ilavesi (DK2) grubu dışında HP içeriğinin artmasina sebep olurken $(\mathrm{P}<0.001)$, toplam nitrojen içerisindeki $\mathrm{NH}_{3}-\mathrm{N}$ miktarının düşmesini $(\mathrm{P}<0.001)$ sağlamıştır. Amonyağa bağlı nitrojenin, toplam nitrojene oranı $88.55-142.16 \mathrm{~g} / \mathrm{kg} \quad \mathrm{TN}$ arasında değişmiştir. En düşük $\mathrm{NH}_{3}-\mathrm{N}$ miktarı TK3 ilavesiyle sağlanmıştır. Suda çözünebilir karbonhidrat içerikleri kontrol grubunda (8.00 g/kg KM), DK gruplarinda sirasiyla $(8.90, \quad 11.30, \quad 7.32 \mathrm{~g} / \mathrm{kg} \quad \mathrm{KM})$ ve TK gruplarinda $(6.62, \quad 11.68, \quad 7.67 \mathrm{~g} / \mathrm{kg} \quad \mathrm{KM})$ olarak bulunmuştur. Muamele gruplarında en düşük SÇK içeriği TK1 grubunda, en yüksek değerler DK2 ve TK2 grubu silajlarda tespit edilmiştir $(\mathrm{P}<0.001)$.

En yüksek LA içeriği (47.84 g/kg KM) DK3 grubunda, en düşük LA içeriği $(6.77 \mathrm{~g} / \mathrm{kg} \mathrm{KM})$ ise kontrol grubunda belirlenmiştir. Yonca silajlarma kefir ilavesi silajların LA içeriklerini önemli düzeyde arttırmıştır $(\mathrm{P}<0.001)$. En yüksek AA içeriği $(19.52$ $\mathrm{g} / \mathrm{kg} \mathrm{KM}$ ) kontrol grubunda, en düşük AA içeriği (3.64 $\mathrm{g} / \mathrm{kg} \mathrm{KM}$ ) olarak DK3 grubunda belirlenmiştir. AA içeriği bakımından muameleler arasındaki farklar istatistiki anlamda önemli bulunmuştur $(\mathrm{P}<0.001)$. Yonca silajlarının BA içerikleri 3.07-17.21 g/kg KM arasında değişmiştir. Yonca silajlarında doz miktarına bağlı olarak silajların, BA içerikleri kontrol grubu silajlara oranla daha düşük tespit edilmiştir $(\mathrm{P}<0.001)$. PA içerikleri kontrol $3.34 \mathrm{~g} / \mathrm{kg} \mathrm{KM}$, DK gruplarında sirasiyla $(2.75,2.99,0.41 \mathrm{~g} / \mathrm{kg} \mathrm{KM})$ ve TK gruplarında $(0.74, \quad 1.63,2.69 \mathrm{~g} / \mathrm{kg} \quad \mathrm{KM})$ olarak bulunmuştur. Muamele gruplarının PA içeriği kontrol grubundan daha düşük bulunmuştur $(\mathrm{P}<0.001)$. Yonca silajlarının KM kaybı \%2.09-2.64 arasinda değişmiş ve yonca silajlarında KM kaybı kontrol grubu silajlarına oranla daha düşük tespit edilmiştir $(\mathrm{P}<0.001)$.

\section{Yonca Silajlarının Mikrobiyolojik Özellikleri}

Yonca silajlarının mikrobiyolojik analiz sonuçları Çizelge 2'de verilmiştir. Silajlarda LAB sayısı başlangiç materyaline oranla tüm gruplarda artmıştır. LAB sayısı kontrol, $5.50 \mathrm{cfu} / \mathrm{g}$ bulunurken, DK gruplarında sirasiyla $(5.60,5.86,5.98 \mathrm{cfu} / \mathrm{g})$, ve TK gruplarında $(6.08,6.07,6.19 \mathrm{cfu} / \mathrm{g})$ olarak tespit edilmiştir $\quad(\mathrm{P}<0.001)$. Yonca silajlarında kefir uygulamasına bağlı olarak silajların maya sayıları artış göstermiş̧tir. En yüksek maya sayısı $6.24 \mathrm{cfu} / \mathrm{g}$ olarak DK1 grubunda tespit edilmiştir $(\mathrm{P}<0.001)$. Yonca silajlarmda sadece kontrol grubunda $2.66 \mathrm{cfu} / \mathrm{g}$ düzeyinde küf tespit edilmiştir $(\mathrm{P}<0.001)$.

\section{Yonca Silajlarında Aerobik Stabiliteye İlişkin Değerler}

Araştırmada, silolamanın 45. günü açılan yonca silajlarına uygulanan 7 günlük aerobik stabilite testi sonuçları Çizelge 3'de verilmiştir. Yonca silajlarında aerobik stabilitenin 7 . gününde belirlenen $\mathrm{pH}$ değerleri sirasıyla kontrol (6.40), DK $(5.65,7.75,5.50)$ ve TK $(5.35,7.90,5.45)$ tespit edilmiştir. Yonca silajlarına kefir ilave edilmesi silajların $\mathrm{pH}$ değerleri üzerinde farklı etkilerde bulunmuştur. Kefir ilave edilen DK2 ve TK2 gruplarında $\mathrm{pH}$ değerleri kontrol grubuna göre daha yüksek tespit edilmiştir $(\mathrm{P}<0.001)$. 
Cizelge 1. Fermantasyonun 45. gününde açılan silajların kimyasal analiz sonuçları

Table 1. Chemical analysis results of silages opened on the 45th day of fermentation

\begin{tabular}{|c|c|c|c|c|c|c|c|c|c|c|c|}
\hline \multicolumn{2}{|l|}{$\begin{array}{l}\text { Muameleler } \\
\text { Treatments }\end{array}$} & $\begin{array}{l}\mathrm{KM}, \% \\
D M, \% \\
\end{array}$ & $\begin{array}{l}\mathrm{pH} \\
\mathrm{pH}\end{array}$ & $\begin{array}{l}\mathrm{HP}, \% \mathrm{KM} \\
C P, D M \%\end{array}$ & $\begin{array}{l}\mathrm{NH}_{3}-\mathrm{N} / \mathrm{TN}^{1} \\
\mathrm{NH}_{3}-\mathrm{N} / \mathrm{TN}\end{array}$ & $\begin{array}{l}\text { SÇK }^{1} \\
W S C\end{array}$ & $\begin{array}{l}\mathrm{LA}^{1} \\
L A\end{array}$ & $\begin{array}{l}\mathrm{AA}^{1} \\
A A\end{array}$ & $\begin{array}{l}\mathrm{BA}^{1} \\
B A\end{array}$ & $\begin{array}{c}\mathrm{PA}^{1} \\
P A\end{array}$ & $\begin{array}{c}\text { KM kaybi, \% } \\
D M \text { loss, \% }\end{array}$ \\
\hline \multicolumn{2}{|c|}{$\begin{array}{l}\text { Silaj Materyali } \\
\text { Silage Material }\end{array}$} & 30.46 & 7.50 & 21.14 & - & 15.45 & & - & - & - & - \\
\hline \multicolumn{2}{|c|}{ Kontrol (Control) } & $27.25 \pm 0.53^{\mathrm{e}}$ & $5.90 \pm 0.00^{\mathrm{a}}$ & $19.80 \pm 0.01^{\mathrm{d}}$ & $142.16 \pm 6.60^{\mathrm{a}}$ & $8.00 \pm 0.29^{\mathrm{bc}}$ & $6.77 \pm 1.43^{\mathrm{e}}$ & $19.52 \pm 3.31^{\mathrm{a}}$ & $17.21 \pm 5.63^{\mathrm{a}}$ & $3.34 \pm 1.04^{\mathrm{a}}$ & $2.64 \pm 0.04^{\mathrm{a}}$ \\
\hline Doğal & DK1 & $28.45 \pm 0.57^{\text {ce }}$ & $5.60 \pm 0.00^{\mathrm{bc}}$ & $19.91 \pm 0.17^{\mathrm{cd}}$ & $91.43 \pm 0.16^{\mathrm{d}}$ & $8.90 \pm 1.29^{b}$ & $13.65 \pm 0.29^{\mathrm{d}}$ & $12.69 \pm 6.27^{\mathrm{bc}}$ & $14.88 \pm 4.75^{\mathrm{a}}$ & $2.75 \pm 0.97^{\mathrm{ab}}$ & $2.09 \pm 0.01^{\mathrm{d}}$ \\
\hline \multirow{2}{*}{$\begin{array}{l}\text { Kefir(Home } \\
\text { Made Kefir) }\end{array}$} & DK2 & $27.95 \pm 0.01^{\mathrm{de}}$ & $5.45 \pm 0.05^{\mathrm{c}}$ & $18.84 \pm 0.14^{\mathrm{c}}$ & $126.80 \pm 14.79^{b}$ & $11.30 \pm 0.63^{\mathrm{a}}$ & $26.63 \pm 2.15^{\mathrm{c}}$ & $6.84 \pm 0.69^{\mathrm{de}}$ & $12.18 \pm 0.32^{\mathrm{ab}}$ & $2.99 \pm 1.28^{\mathrm{ab}}$ & $2.56 \pm 0.02^{\mathrm{b}}$ \\
\hline & DK3 & $31.54 \pm 1.87^{\mathrm{a}}$ & $5.55 \pm 0.05^{\mathrm{bc}}$ & $20.59 \pm 0.21^{\mathrm{a}}$ & $96.90 \pm 7.06^{\mathrm{cd}}$ & $7.92 \pm 0.22^{\mathrm{bc}}$ & $47.84 \pm 4.71^{\mathrm{a}}$ & $3.64 \pm 0.55^{\mathrm{e}}$ & $4.31 \pm 1.22^{\mathrm{c}}$ & $0.41 \pm 0.09^{c}$ & $2.62 \pm 0.02^{\mathrm{a}}$ \\
\hline \multirow{3}{*}{$\begin{array}{l}\text { Ticari Kefir } \\
\text { (Commercial } \\
\text { Kefir) }\end{array}$} & TK1 & $30.52 \pm 0.87^{\mathrm{ab}}$ & $5.70 \pm 0.00^{\mathrm{b}}$ & $20.18 \pm 0.27 \mathrm{bc}$ & $107.97 \pm 0.21^{\mathrm{c}}$ & $6.62 \pm 2.13^{\mathrm{c}}$ & $39.63 \pm 4.54^{\mathrm{b}}$ & $5.41 \pm 1.04^{\mathrm{de}}$ & $11.07 \pm 1.16^{\mathrm{ab}}$ & $0.74 \pm 0.03^{\mathrm{c}}$ & $2.62 \pm 0.00^{\mathrm{a}}$ \\
\hline & TK2 & $29.23 \pm 1.09^{\mathrm{bd}}$ & $5.85 \pm 0.05^{\mathrm{a}}$ & $20.45 \pm 0.20^{\mathrm{ab}}$ & $123.89 \pm 6.13^{\mathrm{b}}$ & $11.68 \pm 0.85^{\mathrm{a}}$ & $23.38 \pm 1.17^{\mathrm{c}}$ & $9.37 \pm 0.77^{\mathrm{cd}}$ & $7.36 \pm 3.19^{\mathrm{bc}}$ & $1.63 \pm 0.66^{\mathrm{bc}}$ & $2.10 \pm 0.03^{\mathrm{d}}$ \\
\hline & TK3 & $29.94 \pm 0.95^{\mathrm{ac}}$ & $5.50 \pm 0.20^{\mathrm{c}}$ & $19.95 \pm 0.07 \mathrm{~cd}$ & $88.55 \pm 0.77^{\mathrm{d}}$ & $7.67 \pm 1.12^{\mathrm{bc}}$ & $25.30 \pm 1.69^{c}$ & $14.55 \pm 1.38^{b}$ & $3.07 \pm 3.07^{\mathrm{c}}$ & $2.79 \pm 0.13^{\mathrm{ab}}$ & $2.31 \pm 0.01^{\mathrm{c}}$ \\
\hline
\end{tabular}

${ }^{1} \mathrm{~g} / \mathrm{kg}$ KM, KM. Kuru madde, HP: Ham protein, $\mathrm{NH}_{3}$-N: Amonyağa bağlı nitrojen, TN: Toplam nitrojen, SÇK: Suda çözünebilir karbonhidrat; LA: Laktik asit, AA: Asetik asit, BA: Bütrik asit, PA: Propiyonik asit. ${ }^{\text {ae }}$ Aynı sütunda farklı harfle gösterilen ortalamalar arasındaki farklar önemlidir $(P<0.001)$. 
Çizelge 2. Fermantasyonun 45. gününde açılan silajların mikrobiyoloji analiz sonuçları

Table 2. Results of microbiology analysis of silages opened on the 45th day of fermentation

\begin{tabular}{lcccc}
\hline $\begin{array}{l}\text { Muameleler } \\
\text { Treatments }\end{array}$ & $\begin{array}{c}\text { LAB, cfu/g KM } \\
\text { LAB, cfu/g DM }\end{array}$ & $\begin{array}{c}\text { Maya, cfu/g KM } \\
\text { Yeast, cfu/g DM }\end{array}$ & $\begin{array}{c}\text { Küf, cfu/g KM } \\
\text { Moud, cfu/g DM }\end{array}$ \\
\hline Silaj Materyali (Silage Material) & & 5.30 & 8.08 & 0.00 \\
\hline Kontrol (Control) & & $5.55 \pm 0.12^{\mathrm{e}}$ & $5.73 \pm 0.01^{\mathrm{e}}$ & $2.66 \pm 1.34^{\mathrm{a}}$ \\
& DK1 & $5.60 \pm 0.00^{\mathrm{e}}$ & $6.24 \pm 0.03^{\mathrm{a}}$ & $0.00 \pm 0.00^{\mathrm{b}}$ \\
Doğal Kefir (Home Made Kefir) & DK2 & $5.86 \pm 0.02^{\mathrm{d}}$ & $5.82 \pm 0.03^{\mathrm{d}}$ & $0.00 \pm 0.00^{\mathrm{b}}$ \\
& DK3 & $5.98 \pm 0.06^{\mathrm{c}}$ & $5.91 \pm 0.01^{\mathrm{c}}$ & $0.00 \pm 0.00^{\mathrm{b}}$ \\
& TK1 & $6.08 \pm 0.00^{\mathrm{b}}$ & $5.94 \pm 0.01^{\mathrm{c}}$ & $0.00 \pm 0.00^{\mathrm{b}}$ \\
Ticari Kefir (Commercial Kefir) & TK2 & $6.07 \pm 0.02^{\mathrm{bc}}$ & $6.11 \pm 0.02^{\mathrm{b}}$ & $0.00 \pm 0.00^{\mathrm{b}}$ \\
& TK3 & $6.19 \pm 0.02^{\mathrm{a}}$ & $6.10 \pm 0.02^{\mathrm{b}}$ & $0.00 \pm 0.00^{\mathrm{b}}$ \\
\hline $\boldsymbol{P}$ & & $<0.001$ & $<0.001$ & $<0.001$ \\
\hline
\end{tabular}

KM: Kuru madde, LAB: Laktik asit bakterileri, cfu: koloni oluşturan birim

abc: Aynı sütunda bulunan farklı harfler önemlidir $(\mathrm{P}<0.05)$

Çizelge 3. Yonca silajlarının 7. gün sonunda aerobik stabilite testi sonuçları

Table 3. Aerobic stability test results at the end of the 7th day of alfalfa silage

\begin{tabular}{|c|c|c|c|c|c|}
\hline $\begin{array}{l}\text { Muameleler } \\
\text { Treatment }\end{array}$ & & $\begin{array}{l}\mathrm{pH} \\
p H\end{array}$ & $\begin{array}{ll}\mathrm{CO}_{2} & \mathrm{~g} / \mathrm{kg} \mathrm{KM} \\
\mathrm{CO}_{2} & \mathrm{~g} / \mathrm{kg} \mathrm{DM}\end{array}$ & $\begin{array}{l}\text { Maya, cfu/g KM } \\
\text { Yeast, cfu/g DM }\end{array}$ & $\begin{array}{l}\text { Küf, cfu/g KM } \\
\text { Mould, cfu/g DM }\end{array}$ \\
\hline \multirow[t]{2}{*}{ Kontrol (Control) } & & $6.40 \pm 0.30^{\mathrm{b}}$ & $16.12 \pm 1.57^{\mathrm{b}}$ & $6.58 \pm 0.09^{\mathrm{bc}}$ & $6.63 \pm 0.02^{\mathrm{a}}$ \\
\hline & DK1 & $5.65 \pm 0.15^{\mathrm{c}}$ & $13.32 \pm 3.18^{\mathrm{c}}$ & $6.28 \pm 0.13^{\mathrm{cd}}$ & $0.00 \pm 0.00^{\mathrm{b}}$ \\
\hline \multirow[t]{2}{*}{ Doğal Kefir (Home Made Kefir) } & DK2 & $7.75 \pm 0.05^{\mathrm{a}}$ & $47.24 \pm 0.02^{\mathrm{a}}$ & $6.67 \pm 0.10^{\mathrm{b}}$ & $0.00 \pm 0.00^{\mathrm{b}}$ \\
\hline & DK3 & $5.50 \pm 0.00^{\mathrm{cd}}$ & $10.67 \pm 1.19^{\mathrm{cd}}$ & $5.24 \pm 0.24^{\mathrm{f}}$ & $0.00 \pm 0.00^{\mathrm{b}}$ \\
\hline \multirow[t]{3}{*}{ Ticari Kefir (Commercial Kefir) } & TK1 & $5.35 \pm 0.05^{\mathrm{d}}$ & $9.08 \pm 0.18^{\mathrm{d}}$ & $5.63 \pm 0.15^{\mathrm{e}}$ & $0.00 \pm 0.00^{\mathrm{b}}$ \\
\hline & TK2 & $7.90 \pm 0.20^{\mathrm{a}}$ & $49.13 \pm 1.53^{\mathrm{a}}$ & $7.34 \pm 0.45^{\mathrm{a}}$ & $0.00 \pm 0.00^{\mathrm{b}}$ \\
\hline & TK3 & $5.45 \pm 0.05^{\mathrm{cd}}$ & $8.53 \pm 0.03^{\mathrm{d}}$ & $6.00 \pm 0.04^{\text {de }}$ & $0.00 \pm 0.00^{\mathrm{b}}$ \\
\hline$P$ & & $<0.001$ & $<0.001$ & $<0.001$ & $<0.001$ \\
\hline
\end{tabular}

DK1: 105; DK2: 5x105; DK3: 1x106; TK1: 105; TK2: 5x105; TK3: 1x106

abc: Aynı sütunda bulunan farklı harfler önemlidir $(\mathrm{P}<0.05)$.

Söz konusu dönemlerde belirlenen $\mathrm{CO}_{2}$ üretim miktarları \%8.53-49.13 g/kg KM arasında değişmiştir. En yüksek $\mathrm{CO}_{2}$ miktarı DK2 ve TK2 uygulamalarında tespit edilmiştir $(\mathrm{P}<0.001)$. Aerobik stabilitenin 7 . gününde maya içerikleri kontrol $6.58 \mathrm{cfu} / \mathrm{g}$, DK (6.28, 6.67 ve $5.24 \mathrm{cfu} / \mathrm{g})$ ve TK $(5.63,7.34,6.00 \mathrm{cfu} / \mathrm{g})$ gruplarında tespit edilmiştir $(\mathrm{P}<0.001)$. Araştırmada maya sayıları ile $\mathrm{CO}_{2}$ üretimleri paralellik göstermiştir. Maya içerikleri yüksek olan DK2 ve TK2 gruplarının $\mathrm{CO}_{2}$ değerleride daha yüksek tespit edilmiştir. Yonca silajlarına kefir ilave edilmesi küfü önlemiştir $(\mathrm{P}<0.001)$.
Çalışmada 16SrRNA Dizi analizi sonuçları değerlendirildiğinde, fermantasyon dönemi (45. gün) silajlarda LAB'inden Enterococcus faecium ağırlıklı olmak üzere, Lactobacillus brevis ve Pediococcus pentosaceu baskın türler olarak belirlenmiştir (Çizelge 4). Aerobik stabilite döneminde ise ağırlıklı olarak Lactobacillus plantarum bunun disında Enterococcus gallinarum, Enterococcus casseliflavus, Weissella paramesenteroides, Enterococcus faecalis, Weissella paramesenteroides, Bacillus sp., Lactobacillus brevis olarak belirlenmiştir (Çizelge 4).

Çizelge 4. İzole Edilen LAB'lerinin 16SrRNA Dizi Analizi sonuçları

Table 4. 16SrRNA Sequence Analysis results of isolated LABS

\begin{tabular}{llll}
\hline $\begin{array}{l}\text { Muameleler } \\
\text { Treatments }\end{array}$ & $\begin{array}{l}45 . \text { gün } \\
45^{\text {th }} \text { day }\end{array}$ & AS \\
\hline Kontrol (Control) & & A. brevis & E. gallinarum, E. casseliflavus, W. \\
& & & paramesenteroides \\
& DK1 & L. brevis, E. faecium & L. plantarum, L. brevis \\
Doğal Kefir (Home Made Kefir) & DK2 & P. pentosaceus, E. faecium & W. paramesenteroides, Bacillus sp., \\
& DK3 & L. brevis & L.plantarum, L. brevis \\
& TK1 & P. pentosaceus, E. faecium & L. plantarum, E. faecalis \\
Ticari Kefir (Commercial Kefir) & TK2 & P. pentosaceus, E. faecium & Bacillus sp., E. faecalis \\
& TK3 & E. faecium & L.plantarum, L. brevis \\
\hline
\end{tabular}

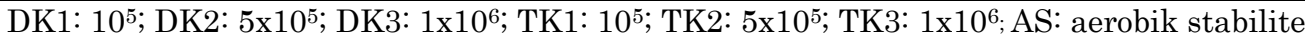




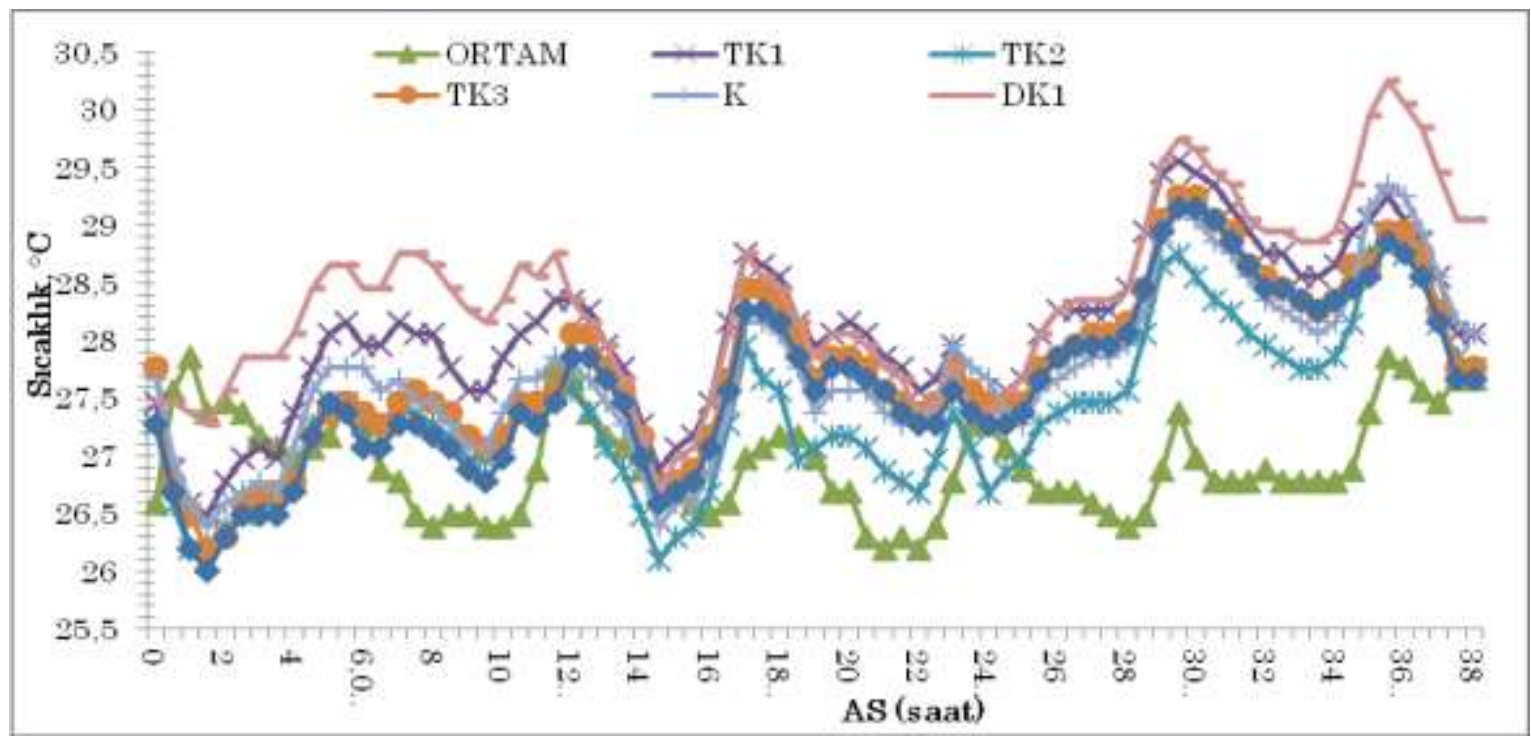

Şekil 1. Aerobik stabilite süresince silajların sensör verileri

Figure1. Sensor data of silage during aerobic stability

Yonca silajlarının 7 günlük aerobik stabilite dönemi süresince sensör verilerine ilişkin sıcaklık değerleri Şekil 1'de verilmiştir. Sensör verilerine ilişkin veriler değerlendirildiğine aerobik bozulma en geç DK3 ve TK3 uygulamalarında tespit edilmiştir.

\section{TARTIŞMA}

Silolanacak bitkisel materyal silo içerisine konulup oksijen ile temasının kesilmesinin ardından, materyal üzerinde bulunan epifitik flora içerisindeki türler arasında bir rekabet başlar ve bu rekabet silaj fermentasyonu aşamalarında da devam eder. Silaj $\mathrm{pH}$ seviyeleri 4.5 ve altına düşünceye kadar bu rekabetin devam ettiği bildirilmektedir (Kızılşimşek ve ark., 2016). Bu nedenle silajın pH'sındaki düşüşün hızlanması, arzulanan bir fermentasyon oluşumu için gereklidir. İyi kaliteli bir silajda $\mathrm{pH}^{\prime}$ nin 3.5-4.0 olması istenmektedir, fakat baklagil silajlarında 4.0 ve üzerindeki $\mathrm{pH}$ değerlerine çok sık rastlanmaktadır (Filya, 2001). Bu çalışmada, kefir ilave edilmesi silajların asitlik düzeyinin artmasına yol açmışsa da, fermantasyonun 45. gününde arzulanan $\mathrm{pH}$ düzeyine ulaşılamamıştır. Silajların başlangıç materyalinde 7.50 olan $\mathrm{pH}$ değeri kefir ilavesi ile muamele gruplarında 5.45-5.90 arasında değişim göstermiştir. Silaj fermantasyon dönemi sirasında ve aerobik stabilite sürecinde, farklı bakteri türleri farklı zamanlarda dominant duruma geçmektedirler. Mevcut araştırmadan elde edilen veriler fermantasyon dönemi ve aerobik stabilite dönemi sonrasında baskın olan türlerin farklılık gösterdiğini ortaya koymuştur. Bu amaçla silaj içinde oluşacak türler arası rekabeti uygun LAB lehine çevirme oldukça önem taşımaktadır (Phillip ve ark., 1990; Pitt, 1990; Stokes, 1992). Bu şekilde $\mathrm{pH}$ düşüşü hızlandırılmakta, protein parçalanması ve KM kayıpları en aza indirilmektedir (Kızılşimşek ve ark.,
2007). Ayrica aerobik bozulma hizl da yavaşlatılmaktadır (İllek, 2006). Bu çalışmada kefir ilavesi silajların $\mathrm{NH}_{3}-\mathrm{N} / \mathrm{TN}$ değerlerinin kontrol grubuna göre düşmesine yol açmıştır. Silolamanın temel amaçlarından biride silolanacak materyaldeki KM kayıplarını mümkün olduğu kadar minimum düzeye indirmektir. Ancak silaj fermantasyonunun homofermantatif veya heterofermantatif yönde şekillenmesine göre KM kayıpları artabilmektedir. Nitekim, fermantasyon heterofermantatif bakteriler tarafından desteklendiğinde $\mathrm{CO}_{2}$ nedeniyle bu kayıplarda artış olabilmektedir (McDonald ve ark., 1991). Bu çalışmadaki veriler değerlendirildiğinde doğal kefir kültürü uygulamalarında fermantasyonun heterofermantatif özellikte, ticari kefir kültürü uygulamalarında ise homofermantatif özellikte şekillendiği söylenebilir. Çalışmada 16SrRNA Dizi analizi sonuçları değerlendirildiğinde, fermantasyon dönemi (45. gün) silajlarda LAB'inden Enterococcus faecium ağırlıklı olmak üzere, Lactobacillus brevis ve Pediococcus pentosaceu baskın türler olarak belirlenmiştir. Aerobik stabilite dönemi sonrasında ise ağırlıklı olarak Weissella paramesenteroides, Bacillus cereus, Bacillus sp. ve Bacillus megaterium türleri tespit edilmiştir. $\mathrm{Bu}$ konuda yapılan çalışmalarda, araştırıcılar, silajlarda en çok rastlanan LAB türleri olarak Lactobacillus ve Streptococcus cinslerine ait türleri bildirmektedir. Silajda Lactobacillus plantarum, Enterococcus faecium, Lactobacillus brevis veya Lactobacillus buchneri gibi anaerobik LAB'nin etkin olması istenirken, Clostridia, Enterobactericiae, Bacilli ve Listeria gibi bakterilerin ise bulunmaması istenmektedir. Bu tür bakteriler, silaj kalitesinin düşmesine ve dolayısıyla da aerobik stabilitenin azalmasina neden olmaktadırlar (Basmacıŏlu ve Ergül, 2002). Çalışmadan elde edilen veriler dikkate alındığında 
özellikle heterofermantatif özelliklere sahip L. brevis bulunduğu silajların aerobik stabilitelerinin daha iyi olduğunu söylenebilir. Misır silajlarına LAB izolatlarının etkilerinin incelendiği bir çalışmada da L. brevisín silajların aerobik stabilitesinde, 6 saatlik bir iyileşme sağladığı tespit edilmiştir (Kızılşimşek ve ark., 2016). L. brevis kefirde yaygin olan bir LAB türüdür bu açıdan bakıldığında aerobik stabilitenin uzatılması açısından önemli olduğu söylenebilir.

\section{SONUÇ}

Araştırma sonucunda, kefir kullanımı yonca silajlarının fermantasyon ve mikrobiyolojik kompozisyon özelliklerini olumlu yönde etkilemiştir. Aerobik stabiliteye ilişkin değerlendirme sonuçları dikkate alındığında; kefirli silajların $\mathrm{CO}_{2}$ üretimi, maya ve değerlerinin az olması dikkat çekicidir. $\mathrm{Bu}$ çalışmada doğal kefir kültürü uygulamalarında izole edilen LAB heterofermantatif özellikte bulunurken, ticari kefir kültürü uygulamalarında ise homofermantatif özellikte LAB'lar izole edilmiştir. Bu anlamda kefirin LAB kaynağı olarak kullanılabileceği ancak doğal kefir kültürü uygulamalarında özellikle LAB türlerinin kefir kültürüne bağlı olarak farklılık göstereceği unutulmamalıdır.

\section{TEŞEKKÜR}

$\mathrm{Bu}$ çalışma NKUBAP.00.24.AR.14.13 numarasıyla, Tekirdağ Namık Kemal Üniversitesi Bilimsel Araştırma Projeleri Koordinasyon Birimi tarafindan desteklenmiştir.

\section{Çıkar Çatışması Beyanı}

Makale yazarları aralarında herhangi bir çıkar çatışması olmadığını beyan ederler.

\section{Araştırmacıların Katkı Oranı Beyan Özeti}

Yazarlar makaleye eşit oranda katkı sağlamış olduklarını beyan ederler.

\section{KAYNAKLAR}

Akyıldız AR 1984. Yemler Bilgisi Laboratuvar Kılavuzu. Ankara, 236 s.

Anonim 1986. The Analysis of Agricultural Material, Reference Book: 427. London, Pp. 428.

Arriola KG, Queiroz OCM, Romero JJ, Casper D, Muniz E, Hamie J, Adesogan AT 2015. Effect of microbial inoculants on the quality and aerobic stability of bermudagrass round-bale haylage. J. Dairy Sci. 98:478-485.

Ashbell G, Weinberg ZG, Azrieli A, Hen Y, Horev B 1991. A simple system to determine the aerobic determination of silages. Can. Agric. Eng. 33: 391395.

Basmacıŏlu H, Ergül M 2002. Silaj mikrobiyolojisi. Hayvansal Üretim Dergisi 43(1): 12-24.
Cebe Hotun G, Tuna YT, Koç F 2019. Silaj inokulantları kullanarak yapılan araştırmaların meta analitik değerlendirilmesi. Erciyes Tarım ve Hayvan Bilimleri Dergisi.2 (2): 21-34.

Chen J, Stokes MR, Wallace CR 1994. Effects of enzyme-inoculant systems on preservation and nutritive value of hay crop and corn silages, J. Dairy Sci., 77: 501-512.

Daniel JLP, Checolli M, Zwielehner J, Junges D, Fernandes J, Nussio LG 2015. The effects of Lactobacillus kefiri and L. brevis on thefermentation and aerobic stability of sugarcane silage. Animal Feed Science and Technology 205: 69-74.

Efe E, Bek Y, Şahin M 2000. SPSS’te çözümleri ile istatistik yöntemler II. Kahramanmaraş Sütçü İmam Üniversitesi Rektörlüğü Yayınları, Kahramanmaraş, 223s.

EFSA 2013. Scientific Opinion on the safety and efficacy of Lactobacillus kefiri (DSM 19455) as a silage additive for all animal species. EFSA J. 4, 1-10, http://dx.doi.org/10.2903/j.efsa.2013.3177, Available online: http://www.efsa.europa.eu/en/ efsajournal/ doc/3177.pdf

Filya İ 2001. Silaj fermantasyonu. Atatürk Üniv. Ziraat Fak. Dergisi, 32 (1): 87-93.

Illek J 2006. Health risk posed by feding low quality silage. 12. International Symposium on Forage Conservation. Brno, Czech Rep. April 3-5, 2006, p: 129-130.

Kızılşimşek M, Öztürk Ç, Küsek M, Mokhtar NEP, Ertem P 2016. Doğal vejatasyondan izole edilmiş ve belirli özelliklerine göre seçilmiş olan 10 adet lab izolatının misır silajının fermantasyon profili ve aerobik stabilitesi üzerine etkileri. Tarla Bitkileri Merkez Araştırma Enstitüsü Dergisi, 25 (Özel say1-2): 278-284.

Kızılşimşek M, Schmidtt RJ Kung LJr 2007. Effects of a mixture of lactic acid bacteria applied as a freeze-dried or fresh culture on the fermentation of alfalfa silage. J. Dairy Science. 90 (12): 5698-5705.

Kleinschmit DH, Schmidt RJ, Kung L 2005. The effects of various antifungal additives on the fermentation and aerobic stability of corn silage. J. Dairy Sci. 88:2130-2139.

Koç F, Coşkuntuna L 2003. Silo yemlerinde organik asit belirlemede iki farkl metodun karşılaştırılması. Hayvansal Üretim, 44 (2): 37-47.

Kung L Jr, Muck RE 1997. Animal Response to Silage Additives. Pages 200-210 in Proc. Silage: Field to Feedbunk North American Conference. NRAES99. Northeast Regional AgriculturalEngineering Service, Ithaca, NY.

McDonald P, Henderson N, Heron S 1991. The Biochemistry of Silage Cambrian Printers Ltd., Aberystwyth, 340p. 
Muck RE, L Kung Jr 1997. Effects of silage additives on ensiling. Pages 187-199 in Proc. Silage: Field to Feedbunk North American Conference. NRAES99. Northeast Regional Agricultural Engineering Service, Ithaca, NY.

Özpınar A 2012. Kefir ve bozanın in vitro antioksidan aktivitelerinin araştırılması. Yüksek Lisans Tezi, Yıldız Teknik Üniversitesi, Fen Bilimleri Enstitüsü, Kimya Anabilim Dalı, İstanbul.

Phillip LE, Underrhill L, Garino H 1990. Effects of treating lucerne with an inoculum of lactic acid bacteria or formic acid upon chemical changes during fermentation, and upon the nutritive value of the silage for lambs. Grass and Forage Sci., 45 (3): 337-344.

Pitt R 1986. Microbial and enzymatic additives for ensiling. 54th, (pp. 137-147). Cornell Nutrition Conference for Feed Manufacturers. Proc Cornell Nutr Conf Feed Manuf 199.

Pitt RE 1990. The probability of inoculant effectiveness in alfalfa silages. American Society of Agricultural Engineering. 33:1771- 1778.

Playne MJ, McDonald P 1966. The Buffering Constituent of Herbage and of Silage, J. Sci. Food. 17(6): 264-268.
Seale DR, Pahlow G, Spoelstra SF, Lindgren S, Dellaglio F, Lowe JF 1990. Methods for The Microbiological Analysis of Silage, Proceeding of The Eurobac Conference, 147. Uppsala.

Silva VP, Pereira OG, Leandro E, Silva T Da, Ribeiro K, Mantovani H, Santos S 2016. Effects of lactic acid bacteria with bacteriocinogenic potential on the fermentation profile and chemicalcomposition of alfalfa silage in tropical conditions. J. Dairy Sci. 99:1895-1902.

SPSS Inc. 2007. SPSS for Windows, Version 16.0. Chicago, SPSS Inc.

Stokes MR 1992. Effects of an enzymes mixture, an inoculant and their interaction on silage fermentation and dairy production. Journal of Dairy Science. 75:764-773.

Supelco 1998. Analyzing fatty acids by packed column gas chromatography, Sigma-Aldrich Corp, Bulletin 856, Bellefonte, PA.

Zwielehner JC, Schoendorfer K, Schatzmayr G 2014. A meta-analysis of Lactobacillus kefiri DSM 19544 and Lactobacillus brevis DSM 23231 as silage inoculant in whole plant maize silage. In: Proc. Int. Sci. Conf. Probiotics and Prebiotics, Budapest, Hungary, p. 173. 